\title{
CARNEIRO DA CUNHA: ANÁLISE DA ATUAÇÃO POLÍTICA NA PROVÍNCIA DA PARAHYBA DO NORTE (1874-1876)
}

\author{
Suenya do Nascimento Costa ${ }^{1}$
}

Jean Carlo de Carvalho Costa ${ }^{2}$

\begin{abstract}
Resumo
Este artigo pretende apresentar temas sobre instrução e progresso para a província da Parahyba do Norte presentes na atuação política de Silvino Elvídio Carneiro da Cunha, assim como conhecer sua trajetória intelectual e as ideias propostas por esse sujeito diante do momento histórico em contexto local. O recorte delimitado é de 1874-1876, período em que Carneiro da Cunha ocupa o lugar de presidente da Província da Parahyba do Norte e mostrava preocupações em torno das reformas necessárias para inserção província na modernidade. Este intelectual abordou vários assuntos que perpassaram sua agenda política. Apontaremos aqui temas referentes à instrução pública, Escola de Educandos Artífices, Escola Normal, escolas noturnas e métodos de ensino, além de construção estradas de ferro e a revolta de quebra-quilos que ocorreu na província paraibana. Todas estas questões foram encontradas em seus relatórios presidenciais, os quais nos serviram de fontes para este texto.
\end{abstract}

Palavras-chave: Carneiro da Cunha. Instrução. Modernidade. Parahyba do Norte.

\section{CARNEIRO DA CUNHA: ANALYSIS OF THE POLITICAL ACTING IN THE PROVINCE OF NORTH PARAHYBA (1874-1876)}

\begin{abstract}
This article intends to present themes about instruction and progress to the Province of North Parahyba present in the political actuation of Silvino Elvídio Carneiro da Cunha, as well as knowing their intellectual trajectory and the ideas proposed by this subject before the historic moment in the local context. The delimited cutting is of 1874-1876, period in which Carneiro da Cunha occupies the president's place of the Province of North Parahyba and showed concerns around the necessary reforms to insertion province in modernity. This intellectual boarded several subjects that went by his political diary. We will point here to themes related to the public education, School of learners artisans, Normal School, to nocturnal schools and teaching methods, besides to building railroads and the revolt of break-kilogram that occurred in the Province of Paraíba. All these questions had been found in his presidential reports, which served us of sources for this text.
\end{abstract}

Keywords: Carneiro da Cunha. Instruction. Modernity. North Parahyba. 


\title{
INTRODUÇÃO
}

O presente artigo é uma análise das ideias educacionais e políticas de Silvino Elvídio Carneiro da Cunha - o Barão de Abiaí $^{3}$ - enquanto presidente da província da Parahyba no período de 1874 - 1876. Tem por objetivo apresentar temas como os de instrução e progresso para a província presentes na atuação política de Carneiro da Cunha e a partir disso conhecer sua trajetória intelectual e as ideias propostas por esse sujeito diante do momento histórico no contexto local. O recorte histórico delimitado é de 1874-1876, período em que Carneiro da Cunha ocupa o lugar de presidente da Província da Parahyba do Norte e mostrava preocupações em torno das reformas necessárias à inserção da provínciana modernidade. Sobre essa categoria, destacamos que:

\begin{abstract}
A palavra "modernidade" tem se prestado a diferentes interpretações de acordo com seus vários interesses de aplicação, apesar de ser traduzida, não raro, com a mesma ideia de "modernização". Desse modo, ela foi interpretada e apropriada de uma maneira geral como "época da história", em que predominariam as categorias da "novidade", da "superação" e do "progresso" [...]. (CARVALHO, 2012, p. 26).
\end{abstract}

Tendo por fontes os relatórios presidenciais de Carneiro da Cunha, analisamos os diversos temas referentes à instrução pública e particular, à Escola de Educandos Artífices, à Escola Normal, às escolas noturnas, religião, construção de estradas de ferro que estreitaram os laços entre as cidades do interior, a maneira como o Presidente lidou com a Revolta dos Quebra-Quilos, entre outras questões que circularam durante o período em que presidia a província paraibana $(1874-1876)$.

Nesse sentido, fazermos esse movimento nos aproxima da historiografia sobre a educação produzida no Brasil, e em particular no contexto local paraibano, e o papel de alguns de seus atores na formação da nação.

Segundo Veiga (2008), a história da educação está sendo entendida como campo de investigações que dá visibilidade a diferentes objetos como a escola, o professor, os alunos, os materiais escolares, entre outros, uma vez que é necessária a atenção aos procedimentos metodológicos e referenciais teóricos que produzem tais objetos como sendo pertencentes à história cultural, política, econômica e social, assim é pertinente "[...] a problematização de um tema da educação, a escola, a partir do referencial da nova história política". (VEIGA, 2008, p. 19).

Vieira (2015) relaciona a História da Educação com a História Intelectual através de uma perspectiva histórica que abrange ao menos dois contextos ao longo da construção do campo em Educação.

O primeiro contexto deu-se na segunda metade do século XIX em que a escrita da História da Educação se configurava a partir das " [...] primeiras narrativas históricas que visavam interpretar o passado educacional com a tradição filosófica" (VIEIRA, 2015, p. 14), ou seja, com a história da filosofia, sobretudo as ideias pedagógicas na produção do campo no Brasil. Este modo de conceber a escrita da história da educação no Brasil é, 
Artigo

doi: $10.20396 /$ rho.v17i2.8645832

conforme afirma o autor, um modo textualista, pois, desconsidera, “[...] a necessidade de estabelecer o relacionamento entre as ideias presentes nos textos examinados (fontes) e os contextos sociais mais amplos, nos quais os autores, as obras, os editores ou os leitores estavam contidos". (VIEIRA, 2015, p. 15).

O segundo contexto apontado por Eduardo Vieira (2015) é uma crítica ao primeiro, voltado para uma escrita filosófica da educação. A partir do final do século XX houve oposição ao modelo textualista e se instaurou entre os pesquisadores do campo da história da educação uma nova concepção de escrita, o modelo contextualista. No Brasil, foi ao final dos anos 1980 que os pesquisadores entenderam a necessidade de renunciar a abordagem das teorias filosóficas e iniciaram uma busca por novos conceitos, novas práticas, novos espaços, novas representações que aproximassem para uma escrita mais histórica da educação brasileira. (VIEIRA, 2015).

No entanto, outros pesquisadores entenderam que é possível debruçar-se sobre as ideias educacionais sem deixar de lado os fatores históricos que estas ideias carregam consigo. Desse modo, duas tradições historiográficas (tanto a História dos intelectuais, quanto a História Intelectual) se fazem presentes nos debates da História da Educação. Com isso, ressaltamos que:

O ponto em comum dessas tradições é a oposição às ideias desencarnadas, de maneira que tanto a história dos intelectuais como a recente história intelectual se revelaram atraentes para aqueles interessados em seguir explorando historicamente a esfera cultural, nas suas dimensões de produção, circulação e recepção de ideias e de crenças em contextos históricos determinados. (VIEIRA, 2015, p. 17).

É nesse contexto da História Intelectual que encontramos respaldo para situar nosso sujeito em questão, Silvino Elvídio Carneiro da Cunha, entendendo seu contexto, sua trajetória e as ideias que permearam sua atuação política.

Após este longo período de ostracismo, no qual a história intelectual era enxergada como campo de pesquisa que visava sujeitos pertencentes da elite e de um grupo social reduzido e elitista, é possível, agora, revisitar esses personagens desmitificando a ideia clássica do protagonismo exercido por certos sujeitos e, com isso, a consequente secundarização de outros, procurando entender o espaço social em que atuaram.

Por isso, é inevitável o conhecimento das produções desses sujeitos em seus contextos, seu tempo histórico, a fim de,

Não nos limitarmos às trajetórias apenas dos "grandes" intelectuais e de descermos até o estrato intermediário dos intelectuais de menor notoriedade, mas que tiveram importância enquanto viveram, e até a camada, ainda mais escondida, dos "despertadores" que, sem serem obrigatoriamente conhecidos ou sem terem sempre adquirido uma reputação relacionada com seu papel real, representaram um fermento para as gerações intelectuais seguintes, exercendo influência cultural e mesmo às vezes política. (SIRINELLI, 2003, p. 246). 
É com essa afirmativa que adentramos na próxima parte deste texto, procurando explicitar a conjuntura e a sociedade na qual Carneiro da Cunha se encontrava além de apresentar um breve esboço biográfico.

\section{TRAJETÓRIA INTELECTUAL DE CARNEIRO DA CUNHA: CONTEXTO SOCIAL, HISTÓRICO E POLÍTICO}

Silvino Elvídio Carneiro da Cunha foi um dos cinco paraibanos que receberam título nobiliárquico de barão. Aos 17 anos, ingressou na Faculdade de Direito de Olinda. Atuou como advogado, político e jornalista, também foi inspetor da alfândega da Paraíba, do Amazonas e do Maranhão. Além de Delegado de Polícia, promotor público e secretário do governo, foi diretor de Instrução Pública e procurador fiscal da Fazenda na Paraíba. Ingressou no Partido Conservador, elegendo-se deputado provincial para a legislatura de 1856-1857 e em 1862. Segundo Socorro Barbosa (2009, p. 56), “A história política da Paraíba teve nesse ilustre homem público um dos seus pontos culminantes pela atividade que exerceu como chefe e orientador do Partido Conservador, cuja agremiação fora fundada com o apoio no poderio de sua ilustre família".

Além da província paraibana, Silvino Elvídio presidiu as províncias do Rio Grande do Norte, Alagoas e Maranhão. Como jornalista, fundou o jornal local A Imprensa, que circulou de 1857 a 1862. Organizou o Jornal da Parahyba, órgão do Partido Conservador, que circulou de 1860 a 1890. (PALMEIRA, 1986). Também era membro do Instituto Histórico e Geográfico de Pernambuco.

Não opôs qualquer dificuldade à implantação da República na Paraíba. Ainda assim, e apesar de monarquista, tentou assumir o Governo do Estado, aderindo ao novo regime como vice-presidente. Carneiro da Cunha faleceu a bordo de um vapor quando esse se aproximava do litoral recifense, vindo de Olinda, em 8 de abril de 1892.

Oriundo de uma família que, com sua influência política, contribuiu para a província da Parahyba do Norte com o desenvolvimento educacional, Silvino Elvídio Carneiro da Cunha se insere no rol da política local dominada por grupos familiares. Sua família atuou de maneira significativa durante o império, sobretudo no que se refere à instrução pública na tentativa de suprir uma demanda educacional de determinados grupos oligárquicos na Província da Parahyba do Norte.

A família Carneiro da Cunha dominava a política no litoral açucareiro desde o final do século XVIII, passando por todo o século XIX, sempre com algum representante ocupando cargos de destaque na política e administração, seja no cenário local ou nacional. Formavam uma família de liderança que se destacaram no Partido Conservador, com participação, na Assembleia Provincial entre 1836 e 1889. (MARIANO, 2011).

A partir da ideia de se pensar o lugar do político e da política no momento de desenvolvimento da escolarização, de modo particular, no século XIX, Veiga (2008) atenta 
para o fato de que a escola é um problema também do âmbito político. Desse modo, a seguir, trataremos da atuação de um dos membros da família Carneiro da Cunha, o Silvino Elvídio, que entre vários projetos, dos quais veremos a seguir, agrupou algumas cadeiras de primeiras letras em um único prédio, o que Ferronato (2008, p. 30), chamou de "[...] uma espécie de prenúncio da era dos grupos escolares".

\section{A INSTRUÇÃO NA PROVÍNCIA DA PARAHYBA DO NORTE: O IDEAL EDUCACIONAL DE PROGRESSO NA VISÃO DE CARNEIRO DA CUNHA}

O debate aqui está em torno de uma análise dos conteúdos que envolvem o tema da Instrução presentes nos relatórios provinciais de Carneiro da Cunha e que foram dirigidos à Assembleia Legislativa durante o exercício de presidente de Província da Parahyba no período de $1874-1875$.

Esse período referente à segunda metade do século XIX foi marcado por algumas transformações no âmbito social, educacional e político em toda sociedade brasileira. Essas mudanças, sobretudo a partir da década de 1870, traziam consigo “[...] uma nova reorganização política que se anuncia via República, enfim, novas questões, tendências, embates políticos e ideológicos que culminam com a inserção em definitivo do país na cena moderna". (COSTA, 2012, p. 150).

O regime monárquico, então, produziu uma “[...] elevada gama de regulamentações e normatizações acerca da instrução pública e particular. Foi a grande contribuição para engendrar o processo de construção da nação brasileira". (PINHEIRO, 2006, p. 5587).

Na Província da Parahyba do Norte foi possível perceber esse movimento na medida em que seus protagonistas vão se engajando em prol das causas da província na segunda metade do século XIX, período de mudanças e transição de regime. Personagens como Manuel Pedro Cardoso Vieira (1848-1880), Albino Gonçalves Meira de Vasconcelos (1850-1908), entre outros, participaram desse engajamento a favor de mudanças na província. Em seus relatórios e discursos, eles trataram de temas como escravidão, instrução para o povo, imigração, reformas educacionais, a seca que assolava as terras paraibanas e as suas consequências.

Desse modo, inserir o sujeito em questão, nesse panorama, nos permite compreender seu posicionamento em relação aos debates surgidos na época sendo, portanto, o meio intelectual, "[...] ao menos para seu núcleo central, um pequeno mundo estreito, onde os laços se atam". (SIRINELLI, 2003, p. 248).

Silvino Elvídio Carneiro da Cunha, em um de seus relatórios presidenciais, chamava a atenção para a importância da Instrução para o cidadão e demonstrava preocupação com a situação do ensino comparado com o progresso que em outros lugares ia ocorrendo: 
Com efeito, um paiz que se rege pelo systema constitucional representativo, e tem diante de si um porvir tão brilhante, não pode deixar de preparar a educação dos que mais tarde tem de dar-lhe dias de gloria em todos os ramos d'actividade humana. Pela nossa parte não temos, é certo, meios bastantes para acompanhar os vôos do progresso, que em outros países vai tendo o ensino público. Entretanto não é isto motivo, para que não cuidemos em fazer alguma cousa, em ir preparando a nossa mocidade para dias mais felizes. (BRASIL, 1874, p. 26).

Para ele, o ensino público do modo que ia, não podia "[...] oferecer garantia de progressivo desenvolvimento [...]" e era necessário fazer uma "[...] profunda alteração". (Ibid, p. 26). Do seu ponto de vista, deveria estar atrelada a uma reforma cuja base seria o ensino livre e a instrução obrigatória.

Carneiro da Cunha expôs sua ideia afirmando que reconhecia a fragilidade do ensino livre no início da história provincial paraibana:

Reconheço que nos primeiros dias de nossa existência política seria um erro, até um perigo, o ensino livre, quando os princípios de ordem e liberdade, o amor ao trabalho, e o incentivo pelos grandes commettimentos não se achavam ainda bem radicados no espirito público, podendo ser facilmente abalado pelas falsas e perigosas douctrinas. (BRASIL, 1874, p. 27, grifo nosso).

Como podemos perceber na citação acima, a questão referente ao ensino livre não foi, de todo modo, aceita pelo presidente em seu início. A preocupação naquele momento estava relacionada com o modo por meio do qual esse ensino livre transmitiria doutrinas que seriam maléficas para a construção de um modelo de sociedade.

Além do mais, podemos inferir que o Estado não apresentava as devidas condições de sustentar tal modo de ensino, visto que se exigia dele uma prática de liberdade num país marcado pela centralização, estrutura senhorial, escravidão e patriarcalismo que impediam a implementação de uma ordem liberal.

Carneiro da Cunha mudou o discurso acerca do ensino livre passando a ser amplamente defendido e, segundo ele, a província da Parahyba do Norte já se encontrava em condições de receber essa mudança. Ele afirmava:

\footnotetext{
Hoje, porém, que todos os partidos, todas as opiniões disputam entre si a primazia no amor por estes bons princípios, hoje que todos, sem excepção de classes e condições, procuram illustrar-se para melhor servirem à causa publica: será um grande erro não deixar largar ás nossas aspirações. Quem souber ensinar que ensine; quem quiser aprender que procure o seu melhor preceptor. O Governo dê a instrucção pública, á que é obrigado: mas aprenda cada um onde quiser, e com quem julgar mais apto. Ocorrectivo do mau professor estará no abandono dos discípulos. (BRASIL, 1874, p. 27, grifo nosso).
}

Esta mudança de opinião de Carneiro da Cunha em relação ao ensino livre pode ser compreendida pelo fato de que o dever de ofertar o ensino e de frequentá-lo são transferidos para a sociedade, ou seja, a iniciativa educacional não é mais do Estado. 
Artigo

doi: $10.20396 /$ rho.v17i2.8645832

Sabemos que a discussão a respeito do ensino obrigatório já se passava por algum tempo. Intelectuais a exemplo de Liberato Barroso já debatiam esse tema na década de 1860. Para ele, "[...] o Estado tem o direito de exigir, como a primeira condição de progresso e de ordem social". (BARROSO, 1867 apud BISERRA, 2013, p. 35).

Paiva (1973, p. 73) afirma que "[...] enquanto a gratuidade do ensino através do sistema público, fora estabelecida desde a lei de 1827, a obrigatoriedade tornou-se um problema". Isso se deu, sobretudo, pela escassez de condições físicas e financeiras de se manter tal estrutura de ensino, pois "[...] a obrigatoriedade do ensino elementar não tinha condições de ser cumprida por falta de escolas, de professores e em face das condições da vida dos próprios alunos. Era um problema teórico discutido pelas elites". (PAIVA, 1973, p. 73).

Carneiro da Cunha também trouxe questões sobre a formação dos professores. A fundação das escolas normais vinha se arrastando desde os anos 1860. Conforme Paiva (1973, p. 75) “[...] somente nas últimas décadas do Império é que elas se multiplicam”.

O presidente percebia a necessidade de uma capacitação do professorado da província e via na escola normal o lugar para que a instrução pública paraibana tivesse esses professores preparados visando à importância sócio-educacional para a Província da Parahyba do Norte. Para que isso se concretizasse, ele demonstrou a necessidade de preparar o pessoal docente, e, para isto, tornou necessária uma escola normal para cada um dos sexos. Em seu relatório afirma que:

É preciso preparar o pessoal docente. Para isto torna necessária uma escola normal para cada um dos sexos, onde sejam preparados os que se destinarem ao professorado. Esta medida é urgente, sob pena de continuar-se a inundar a província de mestres sem a necessária aptidão, com raras excepções. (BRASIL, 1874, p. 27).

A cadeira de ensino normal foi criada e regulamentada por Silvino Elvídio Carneiro da Cunha através da Lei $\mathrm{n}^{\circ}$. 564 de 28 de setembro de 1874. Tinha por finalidade formar professores apenas do sexo masculino para exercer as atividades instrucionais inerentes ao ensino primário. $\mathrm{O}$ seu funcionamento estava previsto para acontecer nas dependências do Liceu Provincial. Para ele, pensar uma escola normal para a província paraibana seria "[...] offerecer garantia de progressivo desenvolvimento". (BRASIL, 1874, p. 26).

Mesmo a ideia e os discursos proferidos pelos políticos, intelectuais, e demais sujeitos da sociedade paraibana de que era necessário um professor preparado numa instituição que se voltasse para essa finalidade, buscando com isso a melhoria da instrução, essa foi, por muito tempo, protelada enquanto institucionalização pelos líderes políticos. Concordamos com Araújo (2010, p. 147), que:

[...] de fato havia o debate, entretanto, até aquele momento, nenhuma proposta no sentido de efetivar a implantação de uma escola normal autônoma pedagógica e administrativamente foi apresentada, tampouco a tão solicitada unificação do ensino foi efetivada tanto do ponto de vista legal quanto prático. 
Artigo

doi: $10.20396 /$ rho.v17i2.8645832

Nessa esteira de pensamento compreendemos que o componente causador dessa situação, está atrelado ao campo político, considerando, pois, cada momento históricosocial cujas prioridades, representações, oscilam do momento histórico, político e social vivido. (ARAÚJO, 2010). No entanto, apesar desse distanciamento entre os discursos e a prática em torno da formação do professor não podemos deixar de ressaltar que até a criação da Escola Normal da Parahyba no final de 1883 e sua efetiva normatização em 1884, muitos foram os debates políticos em prol dessa institucionalização. E nesse sentido, Carneiro da Cunha se insere neste debate de promover na província tal empreendimento. Ou seja, "[...] a ideia e a necessidade de formar professores através de uma escola normal, não caíram no arrefecimento”. (ARAÚJO, 2010, p. 171).

A professora Rose Araújo observa que,

[...] no confronto político e ideológico entre conservadores e liberais, que caracterizava a conjuntura tanto em nível nacional quanto local, Silvino Elvídio Carneiro da Cunha - Barão de Abiahy - na ocasião estava na posição de líder do grupo conservador local [...]. Não deixou de tomar parte e/ou deixar seu registro em defesa da institucionalização da Escola Normal da Parahyba do Norte. Na condição de gestor provincial, fundamentando-se nos princípios iluministas do letramento, do progresso e da civilização, como mecanismos de regeneração social, não obstante sem apresentar uma proposta de funcionamento e/ou de instalação, enfatizou a necessidade de estabelecer o ensino primário obrigatório como também uma escola normal. (ARAÚJO, 2010, p. 171).

Desse modo, enxergamos o presidente Silvino Elvídio Carneiro da Cunha como um indivíduo preocupado com os problemas da província colocando em pauta a importância de qualificar adequadamente o professor como membro indispensável nestes novos rumos vislumbrados para os quais a província paraibana, e também o Brasil, estavam sendo encaminhados.

As aulas noturnas também estavam na pauta das discussões daquele período. Um dos intérpretes da história da educação na Paraíba, José Baptista de Mello, relata que no governo de Carneiro da Cunha "[...] foram instalados os primeiros cursos noturnos destinados à instrução de adultos". (MELLO, 1956, p. 52). Os relatórios de Carneiro da Cunha confirmam a criação dessas escolas noturnas na capital e outras pelo interior da província como podemos perceber no relatório de 7 de agosto de 1874:

Por acto de 24 de fevereiro deste anno criei nesta capital 6 cadeiras, sendo 4 do sexo masculino, e 2 do feminino. D'aquellas, 2 d'aula nocturna, que foram inauguradas com toda solenidade no dia 3 de maio ultimo [...] além destas há ainda as aulas nocturnas do sexo masculino das cidades de Campina Grande e Mamanguape, e povoação da Bahia da Traição, as quaes são frequentadas por 76 alunnos. (BRASIL, 1874, p. 29, grifo nosso).

Nesse sentido, várias aulas e cursos noturnos foram criados com o objetivo de promover os rudimentos da leitura, escrita e aritmética básica das quatro operações para as camadas mais amplas da sociedade. E a documentação nos apresenta de maneira quantificada o número de cadeiras criadas e de aulas noturnas assim como a frequência de alunos nessas aulas da província da Parahyba do Norte: 


\section{Revista HIIST'TEIDIBIR On-lime}

Em virtude de leis provinciaes, votadas em vossa ultima sessão, foram criadas 8 cadeiras do sexo masculino nas povoações de Jericó, Moreno, S. José de Misericordia, Pombas, S, Thomé, Caraúbas, Bodocongó e Riachão do Bacamarte e 4 do sexo feminino nas povoações de Santa Rita, Araruna, Araçagy e Alagoa do Monteiro, ao todo 12 cadeiras. D’ahi vereis que durante a minha administração forão criadas mais 20 aulas d’instrucção primária, sendo 14 do sexo masculino, e 6 do feminino, elevando-se o numero das cadeiras actualmente a 130, á saber 93 do sexo masculino, e 37 do feminino.[...]A frequencia de todas as cadeiras é de 3303 alumnos, sendo 2363 do sexo masculino, inclusive os das aulas nocturnas, e 940 do sexo feminino. (BRASIL, 1874, p. 29, grifo nosso).

A educação voltada para as camadas pobres da sociedade se constituiu em uma preocupação das elites após a emancipação política do Brasil. Nesse caso, o papel da educação nesse processo de consolidação do Estado era entendido como mecanismo de normatização e bom funcionamento da sociedade. Assim, destacamos outro ponto relevante nos relatórios de Carneiro da Cunha que era o Colégio de Educandos Artífices da Paraíba. Estas instituições atuavam sob a perspectiva de formação e de moralização dos “[...] homens pobres desvalidos". (BEZERRA; FERREIRA; KULESZA, 2008).

Carneiro da Cunha sugeriu a possibilidade de acrescentar outras oficinas como marceneiro e ferreiro às já existentes de alfaiate e de sapateiro que segundo ele, "[...] de muita utilidade prestariam pela sua importância”. (BRASIL, 1874, p. 32).

Para isso, ele via a necessidade de aumentar as instalações do colégio e melhorar o instrumental das oficinas que estavam em péssimas condições.

Como podemos verificar em sua fala, para executar estas reformas, “[...] far-se-há indispensável o aumento das proporções do edifício, o que se conseguirá com pequeno dispêndio". (BRASIL, 1874, p.32). E afirmava que estas novas oficinas, naquele momento, não poderiam ser abertas devido aos gastos públicos que elas acarretariam, "Actualmente, porém, não o devo: por isso que importaria um augmento das despesas publicas, attenta a necessidade de dous mestres para dirigi-las. [...] Ainda não perdi esta esperança, precisando apenas que a Provincia tome melhor face". (BRASIL, 1874, p. 32).

Durante todo o período de funcionamento (1866 - 1874), o Collegio de Educandos Artífices manteve o fornecimento de materiais de forma bastante precária. Podemos verificar esta situação em relatório de 1874:

Este estabelecimento d'educação, ainda que acanhado em suas proporções, vai prestando alguma utilidade. É pena que a Provincia actualmente não esteja em condições de dar-lhe maior desenvolvimento. (BRASIL, 1874, p. 31).

No referido relatório, Carneiro da Cunha traz a tabela com dados da receita financeira do Colégio. Ele afirma que é pouca a renda destinada e garante que irá procurar o diretor do estabelecimento para tomar as medidas convenientes.

Todavia, no ano seguinte, em relatório de 1875, Carneiro da Cunha escreveu que decidiu extinguir o Collegio de Educandos Artífices alegando que a província exigia 
medidas econômicas que resultariam em cortes de despesas e a instituição constituía um ônus muito elevado para a província. Cada dia as despesas do Collegio dependiam mais dos repasses do Tesouro Provincial. Dessa forma, afirmou o presidente que:

\begin{abstract}
Nestas condições, e quando a província exigia medidas econômicas d'alcance, não hesitei em decretar a extincção d'aquelle estabellecimento, como fiz, autorisado pelo art. $245 \S 1 .^{\circ}$ da lei n..$^{\circ} 592$ de 12 de outubro do anno passado, transferindo para a companhia de aprendizes marinheiros os menores, que tinhão a idade legal, e forão julgados aptos em inspecção de saúde, sendo eleminados nesta occazião 15,12 dos quaes erão maiores de 17 annos, e como taes não podião ter ingresso naquela utillissima instituição, e 3 julgados incapazes. Deste modo fiz um grande beneficio á tantos desvalidos, que se achavão sob a protecção da província, que os não podia manter, ao passo que o Governo Imperial empenha-se com esforço, á fim de dar todo desenvolvimento á companhia de aprendizes marinheiros nas províncias. E para não fazer injustiça aos funccionarios públicos, que alli se achavão empregados, removi o director do estabelecimento para o da instrucção publica, vago, sendo adidos á respectiva repartição o secretario e porteiro, que muito bons serviços ali prestarão, tornando-se até imprescindível o primeiro á falta d'um empregado, que auxilie ao ajudante do Secretario. (BRASIL, 1875, p. 19 - 20).
\end{abstract}

Compreendemos esta citação do presidente ao analisarmos o que nos diz Horácio de Almeida, que, na segunda metade do século XIX,

Crescia o número de escolas, mas sempre que uma crise afetava a economia da Província, fosse proveniente de seca ou queda nos produtos de exportação, o remédio estava no fechamento dos estabelecimentos de ensino, como medida restauradora das finanças públicas. (ALMEIDA, 1978; [1966], p. 141).

Como pudemos perceber, a administração do Collégio de Educandos Artífices se deparou com inúmeros problemas, sobretudo do ponto de vista financeiro com a falta de recursos, de material e de pessoal.

Importante destacarmos que em todas as províncias do Brasil Império, a organização do ensino a partir destas instituições foi pensada na perspectiva da busca pela manutenção da ordem social e a educação tendo importante papel para o desenvolvimento de uma sociedade moderna. Podemos perceber esse fato nos relatórios de Carneiro da Cunha em citação que segue abaixo:

Um dos primeiros cuidados do Governo e dos corpos legislativos a educação popular, fonte principal de todo o bem, já em relação ao adiantamento moral e intelectual, já em relação ao desenvolvimento industrial, e já finalmente em relação à estatística criminal. (BRASIL, 1874, p. 32, grifo nosso).

Percebemos na fala de Carneiro da Cunha que a educação para esse determinado grupo de pessoas era um dos meios de evitar os índices criminais, sendo assim, o objetivo de instituições voltadas para a população desfavorecida "[...] parecia ser mesmo cuidar de crianças desvalidas ou diminuir a criminalidade". (CANDEIA, 2013, p. 49). 
Com tudo isso até aqui exposto, podemos pensar a instrução como meio gerador de progresso e modernidade e manutenção da ordem juntamente com outros temas discutidos entre os intelectuais nesse importante período de transição, de mudanças políticas, econômicas, sociais e de regime, em que se encontrava o País como um todo. E a Província da Parahyba do Norte não poderia está isenta desse processo.

\section{OUTROS TEMAS PRESENTES EM CARNEIRO DA CUNHA}

Durante a segunda metade do século XIX já é sabido que na província da Parahyba do Norte e no Brasil aconteceram diversas modificações. Uma dessas ocorreu em 1862 quando o governo imperial adotou o sistema métrico decimal. De acordo com a Lei Imperial $\mathrm{n}^{\circ} 1.157$, de 1862 , o sistema de pesos e medidas, então vigente, seria substituído em todo o Império pelo sistema métrico francês.

Em 1872, determinou-se que, a partir de $1^{\circ}$ de julho de 1873 , a legislação imperial entraria em vigor. (SOUTO MAIOR, 1978). Antes da decisão de se implantar o sistema métrico, no Brasil, não existia uma padronização nacional das medidas, logo, havia variação da forma de como se media em cada província e até mesmo de vila e cidade. A solução encontrada pelo governo para facilitar a administração econômica, foi adotar o sistema métrico francês, visto como solução para esse problema de uma falta de padronização nacional dos pesos e medidas.

As mudanças do sistema métrico decimal tiveram impacto nas questões educacionais quando, a partir do artigo $2^{\circ}$ do referido decreto, ordenou que:

As escolas de instrução primária, tanto públicas como particulares, compreenderão no ensino da aritmética a explicação do sistema métrico comparado com o sistema de pesos e medidas atualmente em uso. (BRASIL, 1862).

A padronização de medidas fez parte do currículo brasileiro contemplando o que determinava a lei. A escola foi nesse caso, como na França, utilizada como instrumento oficial para buscar a consolidação do novo sistema através da instrução das crianças.

A partir deste decreto imperial surgiu no interior paraibano, o movimento que ficou conhecido como "A Revolta dos Quebra-Quilos" e essa foi derivada da obrigatoriedade do uso dessas novas medidas e fator determinante para o surgimento desse movimento que começou na Parahyba do Norte e se alastrou por outras vilas e povoados, estendendo-se às províncias de Pernambuco, Rio Grande do Norte e Alagoas.

O movimento ocorreu durante o governo de Carneiro da Cunha que estava à frente da província paraibana. Importante destacar que a postura do presidente nesses acontecimentos contribuiu para a construção de uma imagem que os governantes buscaram 
elaborar, tanto para si quanto para as instituições por eles representadas, ligada a valores em torno da necessidade de estabilidade e de ordem, vislumbrando, assim o progresso.

Observamos, por exemplo, o Relatório apresentado para a Assembléia provincial em que Carneiro da Cunha expressa seu posicionamento diante das manifestações e a preocupação em apresentar uma imagem de ordem e de respeito produzida pela província.

Ele afirma que:

[...] esta província que sempre se distinguiu em todas as éphocas pelo seu conhecimento espírito d'ordem e respeito as autoridades em novembro do ano próxima passado foi vitima em diversos municípios dos agitadores e fanatismo religioso, sob o pretexto dos impostos provinciais e leis de alistamento do exercito e armada e do systema métrico decimal. (BRASIL, 1875, p. 10).

Percebe-se, portanto, que uma manifestação como a de quebra-quilos “[...] destoava desse figurino apaziguador da boa ordem imperial, trazendo à tona a recorrente metáfora do vulcão da anarquia”. (LIMA, 2009, p. 10).

Eram escolhidos os dias de feira para protestar contra os novos pesos e medidas porque era nessa ocasião que as autoridades costumavam cobrar os impostos. Os Quebraquilos, como eram chamados os manifestantes, lutavam contra "[...] o avanço do capitalismo, a serviço do qual se estruturava o sistema métrico decimal" (MELLO, 1995, p. 123), ainda que essa afirmação seja um tanto quanto complexa considerando que esse autor não nos apresenta elementos para afirmar o uso de tal conceito nesse momento específico.

Nesse contexto, Carneiro da Cunha como presidente da província teve uma atuação diante dessas revoltas, o que nos fornece subsídios para entender melhor a postura deste indivíduo frente a esses movimentos. Segundo historiadores, ele tomou posturas rigorosas para combater os revoltosos. Em relatório enviado à Assembleia Legislativa, Carneiro da Cunha afirma o seu interesse em agir com "[...] a mais severa punição das autoridades superiores, heide manter o máximo rigor em sua repressão". (BRASIL, 1874, p. 11).

José Octávio Mello (1995) afirma que o capitalismo veio acompanhado do centralismo imposto pelo Império que por sua vez baixou decretos a exemplo do novo sistema métrico decimal adotado, de um censo geral para a população, também estabelece o registro civil, entre outras medidas. Tendo, pois, a estas decisões do Império, grandes resistências da camada popular e marginalizada da sociedade.

É nesse contexto que observamos as ações tomadas pelos governantes procurando compreender como suas posturas direcionavam as ideias de progresso, civilidade e modernidade para as províncias. Silvino Elvídio Carneiro da Cunha, por exemplo, ao enfrentar o movimento dos Quebra-Quilos, mostrou-se preocupado com a segurança individual e de propriedade na Província da Parahyba do Norte como observamos em Relatório à Assembleia Legislativa: 
Obrigou-me a outra linha de conducta, mantendo a máxima severidade neste serviço; visto como a falta de trabalho e ocupação honesta é que a população ignara procura atentar contra aquelles tão apreciáveis direitos na sociedade. (BRASIL, 1874, p. 11).

Não vamos nos adentrar na questão jornalística aqui neste texto, mas vale destacála como importante lugar de discussões na medida em que nos apresenta subsídios para entender a postura adotada por Carneiro da Cunha neste momento vivido pela província, que foi a Revolta de Quebra Quilos.

A imprensa noticiou os acontecimentos do movimento, sobretudo os jornais $O$ Despertador e A Província, conhecidos por sua postura combatente e diversos comentários políticos que duelavam com o Jornal da Parahyba, órgão do partido conservador, cujo fundador/diretor era Carneiro da Cunha.

Armando Souto Maior (1978), traz em sua obra Quebra-Quilos: Lutas sociais no outono do Império, diversos episódios ocorridos entre os dois jornais acerca do movimento Quebra Quilos. A imprensa teve lugar de destaque, uma vez que ela foi um espaço caloroso de debates. Deste modo percebemos que o jornal é visto como:

[...] um instrumento da imprensa em que circulou a cultura letrada da província. Por muito tempo, essa fonte ficou em segundo plano, em razão do seu caráter tendencioso e imparcial, mas ressurge em diversos trabalhos a partir de 1930 realizados pela Escola dos Annales. O jornal era o lugar da multiplicidade discursiva, onde revelava-se as vozes da "opinião pública". (BISERRA, 2012, p. 13).

Partindo desse ponto de vista, percebemos como o presidente da província recebeu as primeiras notícias sobre o movimento em Ingá, como relata o jornal $O$ Despertador:

Silvino Elvidio Carneiro da Cunha, Presidente da Província, desconsoladamente diria que estava "sem forças para manobrar, sem meios para fazer seguir em perseguição desses desordeiros que certos de nossa fraqueza, ameaçam-nos a cada instante...". (JORNAL O DESPERTADOR apud SOUTO MAIOR, 1978, p. 24).

O jornal, A Província, também não poupou críticas às condutas do presidente:

[...] Não afirmava e ainda não afirma o governo, que tem o decidido apoio da Nação? Pois já chegou a vez de se confessarem fracos e repelidos pelo povo. É pena que só tão tarde o Sr. Silvino se reconhecesse nulidade, sem meios para perseguir as vítmas dos impostos criados por ele, e mais por esse governo patoteiro, que flagela o país para gozar de abundancia, dos confortos, do luxo e de todos os meios de corrupção. [...] Impotentes, fracos e repelidos pela opinião pública tremem nos seus covis, e pedem tropa, mais tropa - único recurso dos déspotas. (JORNAL A PROVÍNCIA apud SOUTO MAIOR, 1978, p. 24).

A Revolta dos Quebra Quilos, embora tenha sido, na sua maioria, com a participação da população de classe baixa, também contou com pessoas da classe média, 
Artigo

doi: $10.20396 /$ rho.v17i2.8645832

líderes religiosos, jornalistas e autoridades locais, levando a se discordar dos pareceres dados pelos historiadores do século XIX e do começo do XX que o Quebra-Quilos havia sido uma revolta de "matutos ignorantes". (SOUTO MAIOR, 1978).

Conforme narra Freire (1982, p. 135), Carneiro da Cunha pediu ajuda ao Governo Imperial, que "[...] enviou uma tropa composta de 700 soldados e sufocou o movimento, rapidamente".

Em 7 de dezembro de 1874, Carneiro da Cunha enviou uma carta ao Ministro e Secretário de Estado dos Negócios da Guerra, pedindo apoio militar. O Ministério da Guerra respondeu o pedido do presidente Silvino e foi escolhido o coronel Severiano Martins da Fonseca, irmão mais velho de Deodoro da Fonseca, futuro presidente do Brasil, para comandar as tropas. Severiano partiu com um batalhão do Rio de Janeiro e, chegando à Província da Parahyba do Norte, o coronel muniu as forças locais e organizou uma pequena cavalaria, partindo, então, em marcha para a cidade de Campina Grande, um dos focos da revolta.

De acordo com Souto Maior (1978. p. 29), a "[...] sedição paraibana não fora subestimada na Corte que percebera, desde logo, o perigo". Nos relatórios eram minuciosas as referências sobre o armamento enviado que incluía três canhões, carabinas, cinquenta mil cartuchos e sessenta mil cápsulas. Segundo, relatos militares, em sua viagem até Areia, a tropa de Severiano prendeu pelo menos 56 pessoas, embora que há registros que alguns conseguiram fugir. Em 25 de dezembro, o batalhão chegou em Campina Grande, a qual havia sido atacada algumas vezes, e sabendo da chegada do exército muitos abandonaram a região. $\mathrm{O}$ coronel Severiano nomeou o capitão Longuinho para comandar parte da tropa com sede em Areia e o capitão Piragibe para atuar em Campina Grande e cercanias. Nesse caso, enquanto o coronel escrevia relatórios para o presidente Carneiro da Cunha e para o imperador, o capitão Longuinho procurava e punia os revoltosos. A esse respeito, nos afirma Armando Souto Maior que:

Pior e mais violenta do que a atuação dos quebra-quilos foi a repressão das forças comandadas pelo capitão Longuinho, hoje tristemente famoso pelos 'coletes de couro', tortura que aplicou aos que lhe foram apontados ou denunciados como quebra-quilos. Amarrados os prisioneiros, eram, em seguida, metidos em grosseiros coletes de couro cru; ao ser molhado, o couro encolhia-se, comprimindo o tórax das vítimas, quase asfixiando-as. (1978, p. 33).

Atos de tortura e outros relatos, sobretudo noticiados na imprensa, apontam que membros foram presos, incluindo homens do clero e bispos. E alguns destes membros do movimento foram até mesmo assassinados, pois a polícia e o exército agiram duramente para por fim a revolta.

Sobre tais acontecimentos, o historiador José Octávio Mello assegura que o “[...] governo reagiu com brutalidade. Até canhões foram deslocados para o teatro dos acontecimentos. A tropa de linha chefiada pelo capitão Longuinho, saqueando engenhos e fazendas, prendeu e espancou à vontade". (MELLO, 1995, p. 122-123). E acrescenta dizendo que a "[...] maneira como Carneiro da Cunha enfrentou os quebra-quilos, na base 
de relatórios alarmistas e repressão policial, fez-se típica da mediocridade da representação política paraibana durante o Império". (MELLO, 1995, p. 123-124). Para o historiador, a rígida subordinação das lideranças paraibanas aos interesses do centro, sob controle de gabinetes, ora conservadores, ora liberais "[...] estimulava o aulicismo, uma das características dos períodos de organização política centrípeta da História do Brasil". (MELLO, 1995, p. 124).

Nesse sentido, destacamos a revolta dos Quebra Quilos, que mesmo tendo durado cerca de um ano tornou bem preocupante para os governos locais das províncias onde ocorreram os conflitos e para o Império, pois levou o Ministério da Guerra a enviar tropas da Guarda Nacional para combater os revoltosos em prol de uma ordem estabelecida, e durante um momento histórico que, no Brasil, denunciava a temperatura social em ebulição. Desse modo,

\footnotetext{
Apesar do pouco destaque dado pela historiografia brasileira, o Quebra-Quilos foi um dos mais importantes movimentos de nossa história, em termos de composição social e de impacto político. O seu aparecimento coincide com uma conjuntura de crise da monarquia e da escravidão, cujos efeitos mais visíveis se manifestam abertamente nas províncias do Norte do Império na segunda metade do século XIX. Foram milhares de participantes e quase 80 localidades conflagradas, entre vilas e cidades da região em foco. (LIMA, 2009, p. 155).
}

Por fim, o movimento, sufocado pelas forças policiais, findou no início de 1875. A modernização que foi imposta era fruto da visão dos próprios governantes, ou seja, da elite imperial. A Revolta do Quebra-Quilos aconteceu, acima de tudo, em nome dos valores e dos costumes, a partir do momento que os homens livres pobres perceberam a interferência direta do governo em seu cotidiano, resistindo à padronização da medição e a uma série de mudanças que implicavam perdas de práticas tradicionais.

Outro fato importante ocorrido na Província da Parahyba do Norte durante este período e que, a partir disso podemos analisar como se deu tal processo na visão de Carneiro da Cunha enquanto presidente provincial, foi a concessão do governo Imperial à Diogo Velho, André Rebouças e Anísio Salatiel Carneiro da Cunha (irmão de Silvino Elvídio) autorizando-os a constituírem uma Companhia que se incuba da construção da Estrada de Ferro que ligaria a capital paraibana à outras cidades no interior. (LEAL, 1989).

Nota-se a importância que essa construção teve para a Parahyba em seu processo de modernidade, urbanização e crescimento econômico. Horácio Almeida (1978) registra que "[...] o progresso entrou na Paraíba pela linha de ferro. Por onde apitava o trem uma emoção nova nascia: a do progresso econômico, mas foi coisa de pouca monta, porque a área beneficiada era demasiado exígua". Defato a extensão da estrada era tímida ainda no Império, foi inaugurado um trecho de $30 \mathrm{~km}$ ligando a capital à Santa Rita. Importante ressaltar que a estrada de ferro Conde d'Eu, cuja construção efetivamente se iniciou em 1880 e foi inaugurada em 1881.

Foi apenas com a República que de fato houve uma expansão ferroviária significativa onde alcançou lugares como Itabaiana, Alagoa Grande (em 1901), Mogeiro, 
Ingá e Campina Grande (em 1907), Bananeiras (em 1913). Portanto, Mello (1995) afirma que na passagem do Império para a República, o principal benefício econômico que a Parahyba presenciou foi a utilização do transporte ferroviário.

Mesmo com as obras só iniciando na década de 1880, o presidente Carneiro da Cunha via na construção da estrada de ferro Conde d'Eu "[...] a primeira alavanca de nosso progresso moral e material". (BRASIL, 1874, p. 4). Em seu relatório presidencial ele pede aos paraibanos que auxiliem "[...] em tão grandioso commettimento, a fim de que ele não encontre tropeços em seus benéficos resultados". Carneiro da Cunha relatou que tem se empenhado para a melhoria da situação financeira na Parahyba e realizou alguns empreendimentos apesar das poucas verbas do cofre provincial, mas contou com a ajuda de alguns "distintos cidadãos" sem diferença de "cores políticas" com isso diz que não poderia haver "duas opiniões em assumpto de universal interesse e prosperidade" que é a construção da estrada de ferro na província. (BRASIL, 1874, p. 4).

O Presidente agradeceu ao Governo Imperial pela concessão da garantia de juros sobre o dinheiro aplicado para as obras enaltecendo o Imperador: “[...] pelas conquistas, reformas sociais e políticas e aperfeiçoamento que tem feito na educação popular e desenvolvimento de seus progressos materiais como telegraphosub-marino e estradas de ferro em pequenas províncias". (BRASIL, 1874, p. 4).

De fato, o progresso material a que se referiu Carneiro da Cunha contribuiu para o urbanismo e modernização de costumes de várias comunidades que não tinham condições de serem consideradas cidades haja vista a falta de estrutura delas. Assim, as estradas de ferro tornavam-se de grande benefício social além de apenas econômico. Segundo Mello (1995, p. 161), “[...] foi o trem combinado com o telégrafo, que reverteu a situação". O historiador acrescenta que, nas cidades em que a estrada de ferro chegava, estas se desenvolviam extraordinariamente e com a virada do século, a cidade da Parahyba teve seu comércio impulsionado pelas casas comerciais e pela cabotagem no rio Sanhauá. (MELLO, 1995).

Ainda entre 1874-1875, Carneiro da Cunha se preocupava com a condição da agricultura da província, e nesse sentido, a concessão da estrada de ferro traria inúmeros benefícios. Em seus relatórios, o presidente relata o "[...] estado de abatimento que se acha a agricultura, primeira fonte de renda da Provincia". (BRASIL, 1874, p. 41).

Ele atribui o estado em que se encontrava a agricultura paraibana a quatro motivos. A saber: a falta de transporte fácil e barato aos produtos; a falta de capital, para fecundar e desenvolver o trabalho; falta de mão de obra na lavoura, e, finalmente, a falta de escolas práticas, que ensinem a melhor maneira de utilizar o terreno, empregando os instrumentos apropriados.

Nesse sentido, o presidente ressaltou a importância do transporte ferroviário como meio de amenizar tal situação agrícola vivida na província: 
Para remediar a falta de transporte aos nossos produtos, só as prodigiosas estradas de ferro, que tem feito uma verdadeira revolução pacífica nas indústrias de todos os Paizes. Felizmente já nos achamos nas vésperas de iniciar este importante melhoramento com a estrada - Conde d'Eu -, cuja companhia a esta hora deverá achar-se organizada em Londres. É certo que ella não aproveitará à todas as zonas productivas; entretanto irá utilizar uma das mais importantes da Provincia, e servirá de elo à todas, que no futuro se prenderão como uma cadêa. (BRASIL, 1874, p. 42).

Diante dessa discussão, primordialmente, a partir dos Relatórios presidenciais e de relatos derivados da própria literatura já escrita sobre esse personagem, é possível associar à representação da modernidade com categorias tais como desenvolvimento, progresso, ordem, civilidade, saúde, segurança entre outros. Do ponto de vista educacional, as ideias e projetos de reforma para a instrução representaram uma característica comum dos intelectuais, pois a educação era vista como espaço para as mudanças sociais, econômicas e políticas da época.

\section{CONSIDERAÇÕES}

O exercício de revisitar os sujeitos que tiveram atuação no debate político da província da Parahyba nos faz compreender como se dá a circulação de ideias entre alguns desses indivíduos, tradicionalmente secundarizados na historiografia corrente, mas que estiveram inseridos nesse amplo debate que atravessa décadas. Nesse sentido, efetuar um levantamento da atuação de Silvino Elvídio Carneiro da Cunha enquanto presidente de província através de seus relatórios presidenciais é identificar seu papel na conjuntura paraibana em um período importante, de mudanças a nível local e nacional.

As discussões na segunda metade do século XIX se voltavam para a inserção do Brasil na modernidade e os temas debatidos pelos intelectuais desse período eram nesse sentido de promover o país a um patamar de nação civilizada, moderna. Os grupos políticos, formados a partir das relações de parentesco, foram incorporados às estruturas sociais e constituíram lideranças ao longo do século XIX. A atuação dos grupos familiares foi fundamental na montagem do processo de autonomia política do Brasil, quando visto a partir da situação na Paraíba.

Dentro dessas discussões destacamos alguns desses temas presentes em Silvino Elvídio Carneiro da Cunha, na medida em que ele se insere nos debates relativos à modernidade, progresso e civilidade. Com isso, pudemos identificar nos relatórios presidenciais seus posicionamentos referentes à instrução como meio de promover o progresso e civilidade para a Província da Parahyba do Norte também por meio da instrução.

Fazer esse movimento de pesquisa nos traz a reflexão teórica de que a educação está associada às dimensões prática e política, ou seja, nos remete à escrita da história política vinculada não só às ideias e teorias formuladas pelos intelectuais, mas, sobretudo, 
aos projetos e ações nos quais se engajaram. (VIEIRA, 2001). Portanto, buscar em Carneiro da Cunha, assim como nos demais intelectuais, o sentido político das suas ideias e as consequências práticas de seus discursos, nos permite compreender como se deu a nossa formação enquanto nação através de alguns personagens brasileiros.

\section{REFERÊNCIAS}

ALMEIDA, Horácio de. História da Paraíba. v. 2. João Pessoa: Editora Universitária UFPB: [1966], 1978.

ARAÚJO, Rose Mary de Souza. Escola normal na Parahyba do Norte: movimento e constituição da formação de professores no século XIX. 2010. 320 f. Tese (Doutorado em Educação) - Universidade federal da Paraíba, João Pessoa, 2010.

BARBOSA, Socorro de Fátima Pacífico (Org.). Pequeno dicionário dos escritores / jornalistas da Paraíba do século XIX: de Antonio da Fonseca a Assis Chateaubriand. João Pessoa: Editora Universitária, 2009. Disponível em: <http://www.cchla.ufpb.br/ jornaisefolhetins/>. Acesso em: 18 jan. 2016.

BISERRA, Ingrid Karla Cruz. Circulação de ideias, intelectuais, educação e modernidade na Parahyba (1870-1889). Plano de trabalho: Fontes bibliográficas primárias (Obras) e impressos (Jornais) - Entre "maiores" e "menores": uma análise sóciohistórica da cena jornalística e sócio-cultural na Parahyba (1870-1889). Relatório final apresentado ao Programa Institucional de Bolsas de Iniciação Científica - PIBIC, João Pessoa, PB: CNPq, 2012.

BISERRA, Ingrid Karla Cruz. História dos intelectuais e a instrução pública no Brasil império: uma análise da obra a província (1870) de Tavares Bastos. Trabalho de Conclusão de Curso. (Graduação em Pedagogia) - Universidade Federal da Paraíba, João Pessoa, PB, 2013.

BRASIL. LEI No 1.157, de 26 de junho de 1862. Substitue em todo o Imperio o actualsystema de pesos e medidas pelo systema métrico francez. Disponível em: <http://www.camara.gov.br/Internet/InfDoc/conteudo/colecoes/Legislacao/ leis1862/ leis\%201862_01.pdf\#page=8>. Acesso em: 23 abr. 2016.

BRASIL. Província da Parahyba do Norte. Relatório Provincial. Relatório apresentado a Assembleia Legislativa da província da Parahyba do Norte em 7 de agosto de 1874 pelo presidente, exm. sr. dr. Silvino Elvídio Carneiro da Cunha. Parahyba, Typ. do Jornal da Parahyba, 1874. Disponível em: <http://brazil.crl.edu/bsd/bsd/601/>. Acesso em 12 set. 2015.

BRASIL. Província da Parahyba do Norte. Relatório Provincial. Relatório apresentado a Assembleia Legislativa da província da Parahyba do Norte em 9 de outubro de 1875 pelo 
presidente, exm. sr. dr. Silvino Elvidio Carneiro da Cunha. Parahyba, Typ. do Jornal da Parahyba, 1875. Disponível em: <http://brazil.crl.edu/bsd/bsd/602/000001.html>. Acesso em: 12 set. 2015.

CANDEIA, Luciano. Mente amore pro pátria docere: a escola de aprendizes artífices da Paraíba e a formação de cidadãos úteis à nação (1909 - 1942). 2013. 318 f. Tese (Doutorado em Educação) - Universidade Federal da Paraíba, João Pessoa, 2013.

CARVALHO, Marcos Vinícius Correa. Moderno, modernidade, modernização: polissemias e pregnâncias. In: FARIA FILHO, Luciano Mendes; GIL, Natália; ZICA, Matheus da Cruz (Org.). Moderno, modernidade e modernização: a educação nos projetos de Brasil - séculos XIX e XX. Belo Horizonte: Mazza Edições, 2012.

COSTA, Jean Carlo de Carvalho. Pensar o Nordeste e os seus sujeitos: circulação de ideias, história dos intelectuais e educação no Brasil. Projeto de Iniciação Científica, apresentado à Pró-reitoria de Pós-graduação e Pesquisa: PRPG/ UFPB, 2012.

FARIA FILHO, Luciano Mendes de; CHAMON, Carla Simone; INÁCIO, Marcilaine Soares. Apresentação. In: FARIA FILHO, Luciano Mendes de; INÁCIO, Marcilaine Soares (Org.). Políticos, literatos, professoras, intelectuais: o debate público sobre educação em Minas Gerais. Belo Horizonte: Mazza Edições, 2009.

FERREIRA; BEZERRA; KULESZA. Livro do aluno e do professor: Manuais técnicos no ensino profissional. In: CONGRESSO BRASILEIRO DE HISTÓRIA DA EDUCAÇÃO: O ENSINO E A PESQUISA EM HISTÓRIA DA EDUCAÇÃO, 5., 2008, Aracaju. Anais... Aracaju, 2008.

FERRONATO. Cristiano. A Instrução Pública na Província da Parahyba do Norte: a Influência da família Carneiro da Cunha - 1823-1874. Revista Tempos e Espaços em Educação, Universidade Federal de Sergipe, v. 1, p. 21-32 jul./dez. 2008. Disponível em <http://www.seer.ufs.br/index.php/revtee/article/view/2191>. Acesso em: 16 jan. 2016.

FREIRE, Carmem Coelho de Miranda. História da Paraíba. Para uso didático. João Pessoa, PB: A União, 1982.

LEAL, José. Itinerário histórico da Paraíba. 2. ed. João Pessoa, PB: A União, 1989.

LIMA, Luciano Mendonça de. Escravidão, liberdade, pobreza e rebeldia no contexto do quebra-quilos (1874-1875). In: CURY, Claúdia Engler; MARIANO, Serioja Cordeiro (Org.). Múltiplas visões: cultura histórica no Oitocentos. João Pessoa: Editora Universitária da UFPB, 2009.

MARIANO, Serioja. Culturas políticas, administração e redes familiares na Paraíba (18251840). Revista de História Saeculum, João Pessoa, jan./jun. 2011.

MELlO, José Baptista de. Evolução do Ensino na Paraíba. 2. ed. João Pessoa: Imprensa Oficial, 1956. 
Artigo

doi: $10.20396 /$ rho.v17i2.8645832

MELLO, José Octavio de Arruda. História da Paraíba: lutas e resistência. João Pessoa: Editora Universitária, UFPB, 1995.

PAIVA, Vanilda Pereira. Educação popular e educação de adultos: contribuição à história da educação brasileira. São Paulo: Loyola, 1973.

PALMEIRA, Balila. Barão do Abiahy: sua vida, sua obra, seus descendentes. Paraíba, 1986.

PINHEIRO, Antonio Carlos Ferreira. As "peculiaridades" da instrução pública e particular na província da Parahyba do Norte (1860 a 1889). In: CONGRESSO LUSO-

BRASILEIRO DE HISTÓRIA DA EDUCAÇÃO, 6., 2006, Uberlândia. Resumos... Uberlândia, 2006. p. 5578-5589. Disponível em: <http://www2.faced.ufu.br/colubhe 06/anais /arquivos/506AntonioCarlosPinheiro.pdf.>. Acesso em: 16 mar. 2016.

SIRINELLI, Jean-Fronçois. Os intelectuais. In: RÉMOND, René (Org.). Por uma história política. Tradução de Dora Rocha. Rio de Janeiro: FGV, 2003.

SOUTO MAIOR, Armando. Quebra-Quilos: lutas sociais no outono do Império. 2. ed. São Paulo, SP: Ed. Nacional, 1978.

VEIGA, Cynthia Greice. História e historiografia da educação no Brasil. Belo Horizonte: Autentica, 2008.

VIEIRA, Carlos Eduardo. História Intelectual e História dos Intelectuais: diálogos acerca da escrita da história da educação. In: VIEIRA, Carlos Eduardo; STRANG, Bernadete de Lourdes Streisky; OSINSKI, Dulce Regina Baggio. (Org.). História intelectual e educação: trajetórias, impressos e eventos. Jundiaí, SP: Paco Editorial, 2015.

VIEIRA, Carlos Eduardo. Intelligentsia e intelectuais: sentidos, conceitos e possibilidades para a história intelectual. Revista Brasileira de História da Educação, n. 16, p. 63-85, 2001. Disponível em: <http://www.sbhe.org.br/novo/rbhe/RBHE16.pdf〉. Acesso em: 22 mar. 2016.

\section{Notas}

\footnotetext{
${ }^{1}$ Pedagoga, Mestre em Educação, na Linha de História da Educação, na Universidade Federal da Paraíba. Integra o Grupo de Estudos e Pesquisas História, Sociedade e Educação no Brasil (HISTEDBR-GT Paraíba), o Grupo de Pesquisa História da Educação no Nordeste Oitocentista (GHENO) e o Grupo História das Instituições e dos Intelectuais da Educação no Brasil (PUC-SP). E-mail: suenyacosta@outlook.com

${ }^{2}$ Doutor em Sociologia pela Universidade Federal de Pernambuco (UFPE). Estágio Pós-Doutoral Sênior no Instituto de Educação, na área de História da Educação, na Universidade de Lisboa (UL), no biênio 2015/2016. Professor associado III, na área de Sociologia da Educação, no Departamento de Fundamentação da Educação (Centro de Educação). Professor pesquisador, habilitado a orientar nos cursos de mestrado e doutorado do Programa de Pós-Graduação em Educação (Centro de Educação) da Universidade Federal da Paraíba (UFPB), na linha de História da Educação, desde 2008. Coordenador da linha de História da Educação no Programa de Pós-Graduação em Educação (PPGE-UFPB) no biênio 2016-2018. Desenvolve pesquisas sobre História Intelectual e dos Intelectuais, Teoria e História da Educação. Lidera o Diretório no
} 
Cnpq do Grupo de Estudos e Pesquisas História, Sociedade e Educação no Brasil (HISTEDBR-GT Paraíba), atuando na Linha História Intelectual e dos Intelectuais, (Auto) Biografias e Estudos de Gênero, além de integrar também o Grupo de Pesquisa História da Educação no Nordeste Oitocentista (GHENO) e o Grupo História das Instituições e dos Intelectuais da Educação no Brasil. E-mail: jeanccosta@yahoo.com.br

${ }^{3}$ Queremos esclarecer que neste texto não nos utilizamos desse termo quando nos referimos ao sujeito em questão, visto que neste recorte histórico ele ainda não havia recebido o título de Barão, o que ocorreu apenas em 1888.

Submetido em: 29/04/2016

Aprovado em: 08/05/2017 